\title{
Padronização da terminologia dos centros médicos universitários e de pesquisa biomédica, no idioma inglês, para envio de artigo de revista ${ }^{1}$
}

\author{
Standardization of the terminology of the academic medical centers and biomedical \\ research centers, in the English language, for journal article sending
}

\author{
Bernardo Hochman ${ }^{2}$, Rafael Fagionato Locali ${ }^{3}$, Renato Santos de Oliveira Filho ${ }^{4}$, Ricardo Leão de Oliveira ${ }^{5}$, Saul \\ Goldenberg $^{6}$, Lydia Masako Ferreira ${ }^{7}$
}

1. Trabalho desenvolvido no Setor de Pesquisa da Disciplina de Cirurgia Plástica da Universidade Federal de São Paulo (UNIFESP)

2. Doutor em Ciências pelo Programa de Pós-Graduação em Cirurgia Plástica da UNIFESP. Co-responsável pelo Setor de Pesquisa da Disciplina de Cirurgia Plástica da UNIFESP

3. Acadêmico do $4^{\circ}$ ano do curso de Medicina da UNIFESP

4. Doutor e Professor Afiliado da Disciplina de Cirurgia Plástica da UNIFESP. Responsável pelo Setor de Pesquisa da Disciplina de Cirurgia Plástica da UNIFESP

5. Pós-graduando de Mestrado do Programa de Pós-Graduação em Cirurgia Plástica da UNIFESP

6. Professor Titular Aposentado da Disciplina de Téenica Operatória e Cirurgia Experimental, e Professor Orientador do Programa de PósGraduação em Cirurgia Plástica da UNIFESP

7. Professora Titular da Disciplina de Cirurgia Plástica e Coordenadora do Programa de Pós-Graduação em Cirurgia Plástica da UNIFESP

\begin{abstract}
RESUMO
Objetivo: Propor uma padronização, no idioma inglês, na formatação da citação da sede da pesquisa. Métodos: A partir das três publicações mais recentes dos 20 primeiros periódicos disponíveis no Portal Brasileiro de Informação Científica Coordenação de Aperfeiçoamento de Pessoal de Nível Superior (CAPES), com maior fator de impacto durante a ano de 2004, segundo levantamento na base de dados ISI Web of Knowledge Journal Citation Reports no biênio 2004-2005, extraíram-se os formatos das citações das sedes de pesquisa. Realizou-se uma analogia ao escalonamento hierárquico institucional da Universidade Federal de São Paulo (UNIFESP), e os formatos mais freqüentes, no idioma inglês, foram adotados como padrão a ser sugerido para citar as sedes de pesquisa ao envio dos artigos. Resultados: Em relação à citação "Departamento", padronizou-se "Department of ..." (sendo “..." o nome em inglês do Departamento), à citação "Programa de Pós-Graduação" "... Program”, "Disciplina" "Division of ...”, "Órgãos, Grupos e Associações" “... Group”, "Setor" "Section of ...", "Centro" "Center for ...", "Unidade" “... Unit" "Instituto" "Institute of ...", "Laboratório" "Laboratory of ..." " "Grupo" "Group of ...".
\end{abstract}

Descritores: Terminologia. Centros Médicos Universitários. Pesquisa Biomédica. Artigo de Revista [Tipo de Publicação].

\begin{abstract}
Purpose: To suggest a standardization, in the English language, the formatting of the citation of the research centers. Methods: From three more recent publications of the first 20 journals available in Brazilian Portal of Scientific Information - Coordenação de Aperfeiçoamento de Pessoal de Nível Superior (CAPES), with bigger factor of impact during the year of 2004, according of information in ISI Web of Knowledge Journal Citation Reports database in biennium 2004-2005, had extracted the formats of citations of the research centers. An analogy to the institutional hierarchie step of the Federal University of Sao Paulo (UNIFESP) was carried out, and the formats most frequent, in the English language, had been adopted as standard to be suggested to cite the research centers for sending articles. Results: In relation to the citation "Departamento", was standardized "Department of ..." (being “..." the name in English of the Department), to the citation "Programa de Pós-Graduação" “... Program”, "Disciplina” "Division of ...., "Órgãos, Grupos e Associações” “... Group “, "Setor" "Section of...", "Centro" "Center for ...", "Unidade" “... Unit ", "Instituto" "Institute of ...", "Laboratório" "Laboratory of ..." and "Grupo" "Group of ...".
\end{abstract}

Key words: Terminology. Academic Medical Centers. Biomedical Research. Journal Article [Publication Type].

\section{Introdução}

As normas editoriais de publicação e abreviação de títulos de periódicos (List of Journals Indexed for Medline), ${ }^{1}$ assim como de Descritores em Ciências da Saúde (DeCS), ${ }^{2}$

padronizaram a divulgação e recuperação da informação científica na esfera da Academia. Com o mesmo intuito, o Comitê Internacional de Editores de Jornais Médicos 
(Uniform Requirements for Manuscripts Submitted to Biomedical Journals: Writing and Editing for Biomedical Publication) atualizou recentemente a uniformação das exigências para manuscritos submetidos a jornais biomédicos, conhecida como Normas de Vancouver. ${ }^{3}$

Apesar dessa atualização conter uma série de normas quanto à formatação do texto, título, referências, dentre outras, não existe uma proposta do padrão exigido no formato de escrita do local de atribuição do estudo. Facultouse a cada periódico atender esse quesito.

Dessa forma, essa lacuna nas normas internacionais de publicação gera uma falta de padronização na versão para o idioma inglês, no formato da citação ou expressão da sede da pesquisa, ao submeter o artigo. O objetivo deste artigo é propor uma padronização, no idioma inglês, na formatação da citação da sede da pesquisa.

\section{Métodos}

Foram identificados os 20 primeiros periódicos indexados e disponíveis no Portal Brasileiro de Informação Científica - Coordenação de Aperfeiçoamento de Pessoal de Nível Superior (CAPES) ${ }^{4}$ da área de Ciências da Saúde, com maior fator de impacto durante a ano de 2004, segundo levantamento na base de dados ISI Web of Knowledge Journal Citation Reports no biênio 2004-2005 (Figura 1). ${ }^{5}$ Dessa seleção de periódicos, foram incluídos apenas os três fascículos mais recentes de cada um, com seleção realizada de forma retro-ativa a partir de novembro de 2005. Destes, apenas consideraram-se as expressões contidas em artigos originais (original article), artigos de revisão (review article) e "notícias e enfoques" (news and views).

Nessa amostragem foram somados todos os formatos das citações no idioma inglês referentes aos locais que sediaram as pesquisas. A proposta de padronização foi baseada em uma analogia às categorias existentes, em idioma português, no escalonamento hierárquico institucional da Universidade Federal de São Paulo (UNIFESP), ${ }^{6}$ a partir do terceiro escalão (Figura 2), segundo a citação mais freqüente para cada categoria.

\begin{tabular}{|lc|}
\hline \multicolumn{1}{|c}{ Periódico } & Fator de Impacto \\
\hline Annual Review of Immunology & 52.431 \\
CA: A Cancer Journal for Clinicians & 44.515 \\
New England Journal of Medicine & 38.570 \\
Nature Reviews. Cancer & 36.557 \\
Physiological Reviews & 33.918 \\
Nature Reviews. Molecular Cell Biology & 33.170 \\
Reviews of Modern Physics & 32.771 \\
Nature Reviews. Immunology & 32.182 \\
Nature & 31.853 \\
Science & 31.538 \\
Annual Review of Biochemistry & 31.223 \\
Cell & 28.389 \\
Nature Immunology & 27.586 \\
JAMA: The Journal of the American & \\
Medical Association & 24.831 \\
Nature Genetics & 24.695 \\
Annual Review of Neuroscience & 23.143 \\
Pharmacological Reviews & 22.837 \\
Nature Biotechnology & 22.355 \\
Lancet & 21.713 \\
Surface Science Reports & 21.350 \\
\hline
\end{tabular}

FIGURA 1 - Os vinte periódicos com maior fator de impacto disponível on-line pelo Portal Brasileiro da Informação Científica-CAPES.

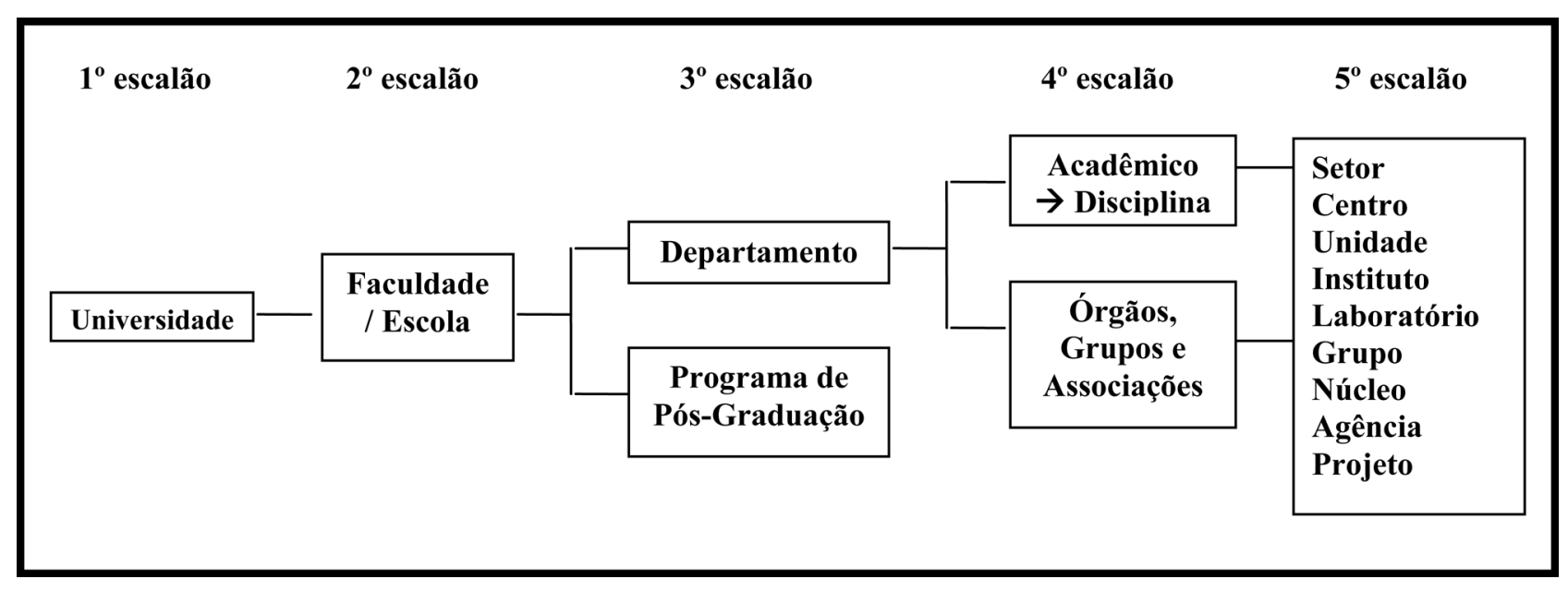

FIGURA 2 - Escalonamento hierárquico institucional da UNIFESP. 


\section{Resultados}

No terceiro escalão, em relação à expressão ou termo "Departamento", houve apenas a expressão "Department of ..." (... nome em inglês do Departamento) em correspondência, com 360 citações. Em relação à expressão "Programa de Pós-Graduação" houve quatro correspondências; em ordem decrescente foram “... Program" (...$=$ nome em inglês do Programa), com 17 citações, "Program in ...", com 9 citações, e "Program of ... " e "Program on ... " com 1 citação cada.

No quarto escalão, em relação à expressão "Disciplina", houve duas correspondências, "Division of ...", com 56 citações, e "Discipline of ..." (... = nome em inglês da Disciplina), com 1 citação. Em relação à expressão “Órgãos, Grupos e Associações”, houve apenas a expressão “... Group” (... = nome em inglês do Órgão, Grupo ou Associação) em correspondência, com 8 citações.

No quinto escalão, em relação à expressão "Setor", houve duas expressões correspondentes, "Section of ...", com sete citações, e "... Section” (... = nome em inglês do Setor), com cinco citações. À expressão "Centro" obtevese "Center for ..." e “... Centre” (... = nome em inglês do Centro), com 62 e 7 citações, respectivamente. Em relação à expressão "Unidade", encontrou-se “... Unit" e "Unit of ..." (... = nome em inglês da Unidade), com 8 e 3 citações, respectivamente. Para o termo "Instituto" registrou-se "Institute of ..." e "Institute for ..." (... = nome em inglês do Instituto), com 93 e 63 citações, respectivamente. O termo "Laboratório" foi traduzido como "Laboratory of ..." e "Laboratory for ..." (... = nome em inglês do Laboratório) com 31 e 3 citações, respectivamente, enquanto o termo "Grupo" por "Group of ..." (... = nome em inglês do Grupo), com 9 citações. Por outro lado, na amostragem, não houve tradução para os termos "Núcleo", "Agência" e "Projeto". E, finalmente, encontrou-se o termo "Branch" com 3 citações, sem correspondência na categoria em questão.
Todas as citações em inglês encontradas estão resumidas na Figura 3. A proposta de padronização, segundo as expressões mais citadas para cada categoria, está descrita na Figura 4.

\begin{tabular}{|lc|}
\hline Expressão no Idioma Inglês & Número de Citações \\
\hline Department of ... & 360 \\
... Program & 17 \\
Program in ... & 9 \\
Program of ... & 1 \\
Program on ... & 1 \\
Division of ... & 56 \\
Discipline of ... & 1 \\
$\ldots$ Group & 8 \\
Section of ... & 7 \\
... Section & 5 \\
Center for ... & 62 \\
... Centre & 7 \\
... Unit & 8 \\
Unit of ... & 3 \\
Institute of ... & 93 \\
Institute for ... & 63 \\
Laboratory of ... & 31 \\
Laboratory for ... & 3 \\
Group of ... & 9 \\
Branch & 3 \\
\hline
\end{tabular}

FIGURA 3 - Quantidade de citações do formato das sedes de pesquisa da amostragem. $(\ldots=$ nome em inglês do Departamento, Programa de PósGraduação, Disciplina, Órgãos, Grupo e Associação, Setor, Centro, Unidade, Instituto, Laboratório ou Grupo)

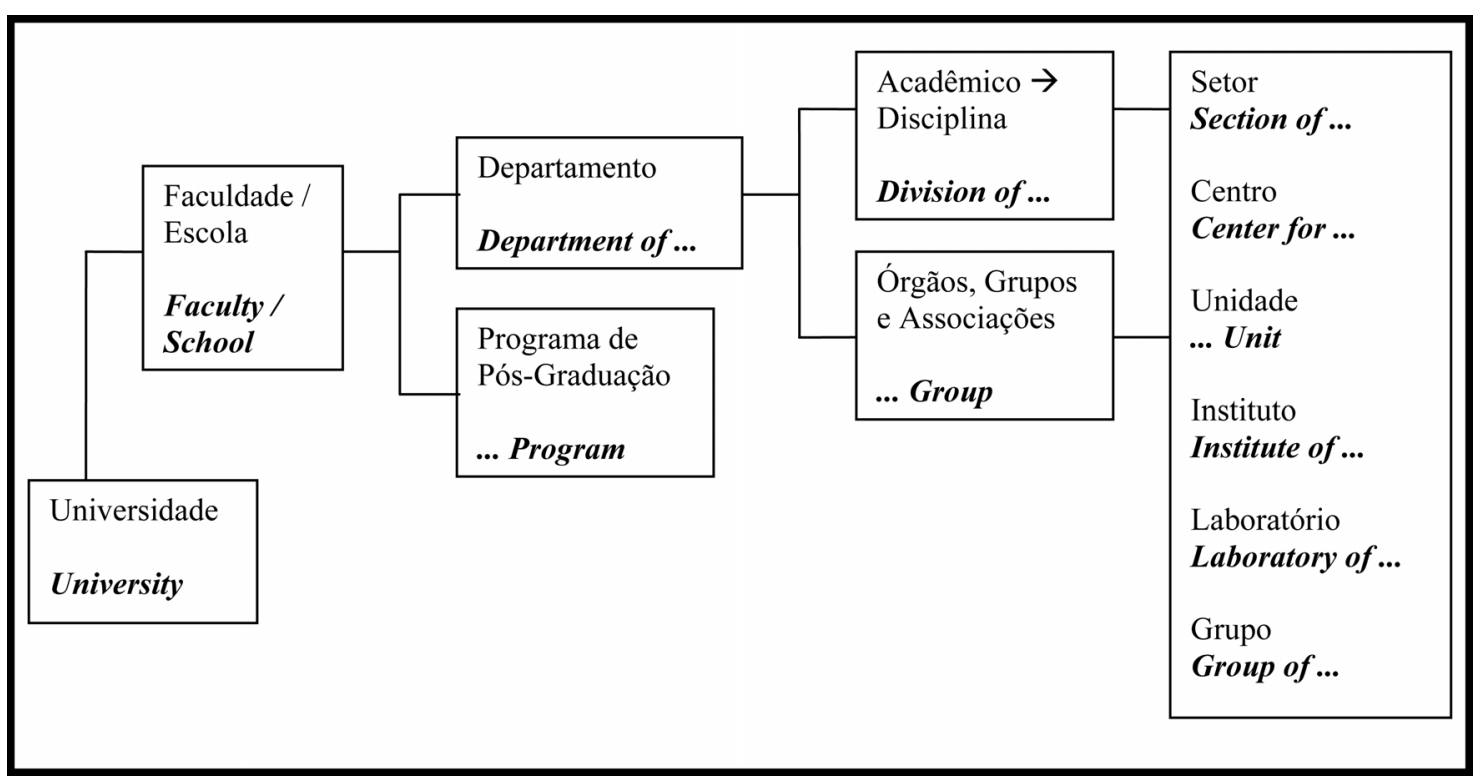

FIGURA 4 - Padronização obtida para o formato das citações de sedes de pesquisa no idioma inglês (em destaque, com letras em itálico, a tradução correspondente; ... = nome em inglês do Departamento, Programa de PósGraduação, Disciplina, Órgãos, Grupo e Associação, Setor, Centro, Unidade, Instituto, Laboratório ou Grupo). 


\section{Discussão}

A necessidade de realizar este estudo de normalização, no idioma inglês, quanto à formatação das citações das sedes das pesquisas para o envio dos artigos aos diversos periódicos, decorreu da falta de uniformação deixada pelo Comitê Internacional de Editores de Jornais Médicos. ${ }^{3}$ Esse fato pode criar dificuldade aos autores quando deparam-se com formatos individualmente padronizados em diversas revistas, e, geralmente, não descritos pelas mesmas.

Optou-se em utilizar as 20 primeiras revistas com maior fator de impacto, no ano de 2004, e disponíveis no Portal Brasileiro de Informação Científica - Coordenação de Aperfeiçoamento de Pessoal de Nível Superior (CAPES), ${ }^{5}$ da área de Ciências da Saúde, pela maior facilidade da pesquisa on-line e, por constituírem esses periódicos uma referência de respeitabilidade internacional.

O escalonamento hierárquico da UNIFESP ${ }^{6}$ foi adotado como padrão por tratar-se de uma instituição pública de âmbito federal, que também é tida como referência nacional e internacional em pesquisas clínica e experimental. Assim, este estudo de compilação e padronização abre uma perspectiva de reflexão para os editores de revistas, no sentido de complementar as normas estabelecidas pelo Comitê Internacional de Editores de Jornais Médicos. ${ }^{3}$ Essa reflexão também pode ser extensiva a outras lacunas deixadas pelas normas de Vancouver, como, por exemplo, a formatação das citações da titularidade acadêmica dos autores ${ }^{7}$.

\section{Referências}

1. National Library Medicine. List of journals indexed for MEDLINE [monograph on the Internet]. Washington: National Library of Medicine; 2005 Jun [cited 2005 Nov 1]. Available from:

ftp://nlmpubs.nlm.nih.gov/online/journals/ljiweb.pdf

2. DeCS Descritores em Ciências da Saúde [base de dados na Internet]. São Paulo: BIREME; [citado 2005 Nov 17]. Disponível em: http://decs.bvs.br/

3. International Committee of Medical Journal Editors. Uniform requirements for manuscripts submitted to biomedical journals. Writing and editing for biomedical publication [text on the Internet]. Vancouver (CA); update 2004 Oct [cited 2005 Nov 1]. Available from: http://www.icmje.org/

4. O Portal Brasileiro da Informação Científica [base de dados da Internet]. Brasília: CAPES; [citado 2005 Dez 10]. Disponível em:

http://www.periodicos.capes.gov.br/portugues/index.jsp

5. Institute for Scientific Information. Journal Citation Reports 2004 Science Edition [database on the Internet]. In: ISI Web of Knowledge version 3.0. Philadelphia: Thomson Scientific; 2005 [cited 2005 Nov 10]. Available from: http://portal.isiknowledge.com/ portal.cgi?DestApp $=$ JCR\&Func $=$ Frame

6. Departamentos Universidade Federal de São Paulo Escola Paulista de Medicina [serial on the Internet]. São Paulo: UNIFESP; [citado 2005 Dez 10]. Disponível em: http://www.unifesp.br/deptos.htm

7. Goldenberg S, Matone J. Academic degrees. Standardization in English language [editorial]. Acta Cir Bras. 2006;21(2):60. Available from URL: http://www.scielo.br/acb.

\section{Correspondência:}

Dr. Bernardo Hochman

Disciplina de Cirurgia Plástica / Departamento de Cirurgia

Universidade Federal de São Paulo

Rua Napoleão de Barros, $715 / 4^{\circ}$ andar

04024-900 São Paulo - SP

Tel:(11) 5576-4118

lydia.dcir@epm.br

bernardohochman@uol.com.br
Conflito de interesse: nenhum

Fonte de financiamento: nenhum

Recebimento: 10/05/2006

Revisão: 12/06/2006

Aprovação: 11/07/2006

\section{Como citar este artigo:}

Hochman B, Locali RF, Oliveira Filho RS, Oliveira RL, Goldenberg S, Ferreira LM. Padronização da terminologia dos centros médicos universitários e de pesquisa biomédica, no idioma inglês, para envio de artigo de revista. Acta Cir Bras. [periódico na internet] 2006 set-out;21(5). Disponível em URL: $\underline{\text { http://www.scielo.br/acb }}$ 